\title{
EFFECT OF BICARBONATE AND HIGH PH ON ROOT GROWTH AND ACCUMULATION OF ORGANIC ACIDES IN TWO RICE CULTIVARS DIFFERING IN SUSCEPTIBILITY TO ZN DEFICENCY
}

Bassioni, Nabila, H.*; S. T. Abou-Zeid*; Y. A. Abd-El Aal" and H. M. A. El-Kotb**

- Soil Sci. Dept. Fac. Agric., Cairo Univ.

** Soil, Water and environment Res. Inst., A. R. C., Cairo, Egypt.

\begin{abstract}
The objective of the present study was to evaluate the effect of bicarbonate and high $\mathrm{pH}$ treatments separately on shoot and root growth and accumulation of organic acids in the roots of two rice cultivars differing in susceptibility to $\mathrm{Zn}$ deficiency. The results indicated that shoot and root dry weight of both cultivars decreased by the treatments with bicarbonate and high $\mathrm{pH}$ and the decrease in shoot and root dry weight were greater when plants grown with bicarbonate than that with high $\mathrm{pH}$. The inhibitory effect of bicarbonate end high pH on shoot and root dry

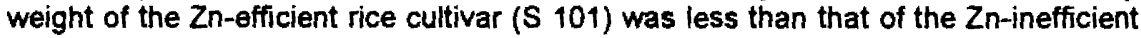
rice cultivar ( $(172)$. Root length was significantly decreased by bicarbonate and high $\mathrm{pH}$ treatments for the $\mathrm{Zn}$-inefficient rice cultivar (G172); whereas was considerably enhanced by bicarbonate and high $\mathrm{pH}$ treatments for the $\mathrm{Zn}$-efficient rice cultivar(S101), and the enhancement of root length in the Zn-efficient rice cultivar (S101) was greater when plants grown with bicarbonate than that with high $\mathrm{pH}$. Both bicarbonate and high $\mathrm{pH}$ treatments increased the concentrations of organic acids (malic, citric, fumaric and succinic) in the roots of both cultivars, but to a greater extent for the $\mathrm{Zn}$-inefficient than for the $\mathrm{Zn}$-efficient cultivars. The results suggest that the impairment of root growth was likely to be the initial action of bicarbonate in inducing Zn-deficiency in low land rice, and the inhibitory effect of

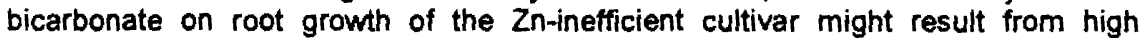
accumulation and an insufficient compartmentation of organic acids in the root cells.
\end{abstract}

\section{INTRODUCTION}

Zinc deficiency in plants is widespread throughout the world. It is estimated that more than $40 \%$ of the soils surveyed in 19 countries are zinc deficient (Graham et al., 1992). In Egypt, zinc is one of the most limiting factors affecting rice production second only to nitrogen. Zinc deficiency of lowland rice occurs widely in almost neutral to alkaline soils, particularly calcareous soils (Sobhy et al, 2002).

Bicarbonate and high $\mathrm{pH}$ combined with low $\mathrm{Zn}$ availability may be involved in the induction of $\mathrm{Zn}$ deficiency for the $\mathrm{Zn}$-inefficient genotypes. The zinc-efficient genotypes are those that grow and yieid normally when grown in soils with low $\mathrm{Zn}$ availability. The susceptibility of rice genotypes to $\mathrm{Zn}$ deficiency was found to be closely associated with high tolerance of plants to elevated bicarbonate concentrations (Yang et al., 1994). Zinc deficiency in the field occurs generally $2-4$ weeks after rice transplanting (Qin, 1988) or 46 weeks after submergence when bicarbonate concentration reaches as high as $40 \mathrm{mM}$ (Forno, et al., 1975). 
Bassioni, Nabila, H. et al.

Shoot growth of the $\mathrm{Zn}$-inefficient rice cultivar was strongly inhibited by bicarbonate, whereas that of the $\mathrm{Zn}$-efficient was not affected (Hajiboland et al., 2003 and Yang et al., 2003). Little information is available, however, concerning the mechanisms how bicarbonate induces $\mathrm{Zn}$ deficiency. Dogar and Hai (1980) indicated that bicarbonate inhibited $\mathrm{Zn}$ absorption by rice roots, but Forno et al, (1975) reported that the primary effect of bicarbonate is to inhibit $\mathrm{Zn}$ translocation from roots to shoots.

One major factor may be the high accumulation of organic acids in root cells through stimulation of phosphoenolpyruvate -carboxylase in cytoplasm induced by bicarbonate or high $\mathrm{pH}$. It has been reported that lime-induced chlorosis in some plants was related to high accumulation of organic acids (Yang et al., 1994) Again; it is unknown whether bicarbonate has a specific effect on organic acid accumulation for $\mathrm{Zn}$-inefficient rice genotypes, or whether high $\mathrm{pH}$ has the same effect. The objectives of this study were to examine the effects of high $\mathrm{pH}$ and bicarbonate separately on root growth and the accumulation of organic acids in $\mathrm{Zn}$-efficient and $\mathrm{Zn}$-inefficient rice genotypes.

\section{MATERIALS AND METHODS}

\section{Primary experiment}

Nine rice cultivars (Giza 171,172,176,177,178,181 and Sakha $101,102,103$ ) were classified based on dry matter production (root plus shoot) at the low $\mathrm{Zn}$ level and Zn-use efficiency. Twenty-days-old seedlings of similar size from the cultivars were selected, sixteen seedlings transplanting together in each 3-liter container containing 2.5-liter from nutrient solution as described by yoshida, (1972), (mM): $\mathrm{NH}_{4} \mathrm{NO}_{3} 1.43, \mathrm{CaCl}_{2} 1.00, \mathrm{MgSO}_{4} 1.64$, $\mathrm{K}_{2} \mathrm{SO}_{4}$ 1.32, $\mathrm{KH}_{2} \mathrm{PO}_{4} 0.32$ and $(\mu \mathrm{M}): \mathrm{MnCl}_{2} 9.5, \mathrm{FeCl}_{3}$ 35.6, $\mathrm{ZnSO}_{4} 0.15$, $\mathrm{CuSO}_{4} 0.15, \mathrm{H}_{3} \mathrm{BO}_{3} 1.9$, and $\left(\mathrm{NH}_{4}\right)_{6} \mathrm{MO}_{7} \mathrm{O}_{24} 0.075$. while zinc were added at 3 levels of zinc as: (zero, 0.08 and $0.15(\mu \mathrm{M})$. Nutrient solution was changed every 5 day and the $\mathrm{pH}$ adjusted daily for $\mathrm{pH}(5.5-6)$.

Thirty days after transplanting, the plants were harvested then separated into shoot and root, rinsed with distilled water and dry weight of shoot and root were recorded after drying at $70 \mathrm{OC}$ in a forced-air oven, then ground and analyzed for zinc.

\section{Main experiment}

Two rice cultivars, one $\mathrm{Zn}$-inefficient (Giza 172) and one $\mathrm{Zn}$-efficient (Sakha 101), were selected for this study from the primary experiment. Seeds were germinated in Petri dishes over three layers of cotton saturated with distilled water. The dishes were then covered and left in the incubator for $48 \mathrm{~h}$ at temperature between $28-30 \mathrm{oC}$. The germinated rice seeds were raised on a nylon net for 5 days in a solution of $0.02 \mathrm{mM} \mathrm{CaSO}_{4}$.

Prior to bicarbonate treatment, all rice seedlings were precultured for 7 days in the same composition of nutrient solution (Yoshida, 1972) as described in the primary experiment. Instead of $\mathrm{FeCl}_{3}$, Fe was supplied as 
FeEDDHA (Ethylene-bis-[2-(0-hydroxypheny) glycine]) at $0.01 \mathrm{mM}$ during this period.

Twelve-day-old seedlings of similar size were selected and transplanted to $3-L$ plastic containers containing the same composition of nutrient solution with $0.1 \mathrm{mM}$ FeEDDHA. Each container had sixteen seedlings. Bicarbonate was supplied at three concentrations: 0,10 , and 20 $\mathrm{mM}$ as sodium bicarbonate. The $\mathrm{pH}$ of the nutrient solution was adjusted daily by $\mathrm{NaOH}$ or $\mathrm{H}_{2} \mathrm{SO}_{4}$ to $\mathrm{pH} 6$ for the control and to $\mathrm{pH} 8$ for the high $\mathrm{pH}$ and bicarbonate treatments. Each treatment was replicated 3 times. Plants were harvested after 0,4 , and 8 days of the start of bicarbonate treatments.

\section{1-Root and shoot dry weight}

Five plants from each replicate of the treatments were used for shoot and root dry weight measurement. Plants were insed with distilled water, separated to shoot and root and blotted between filter papers. Dry weight of shoot and root were recorded after drying at $70^{\circ} \mathrm{C}$ in a forced-air oven.

\section{2-Root length}

Another five plants of each replicate were used for root length measurement. Fresh root was used for root length measurement by using the method described by Newman, (1966).

\section{Method of measuring root length:}

The method is based on the assumption that if a root is laid within an area within which some straight lines lie at random. we should expect that the longer the root the more intersections it will make, on average, with the straight lines. Thus the number of intersections can be used to estimate the length of root by the following equation:

$$
\begin{aligned}
L= & \left(\prod A N\right) / 2 H \\
L & =\text { root length }(\mathrm{cm}) \text { of the counted sample. } \\
A & =\text { area of } s c r e e n \mathrm{~cm}^{2} . \\
N & =\text { number of intersection. } \\
H & =\text { length of hair line in the plain where the root are counted. }
\end{aligned}
$$

The $\mathbf{N}$ is calculated as (Sum of intersection / Sum fietd examined).

Root length per $g$ of counted sample $=U / C$

Where $\mathrm{C}=$ dry weight of the counted sample.

Total length of the root $=(L C) \times$ total dry weight of the root .

\section{3-Organic Acids}

The rest of the plants of each replicate were used for organic acid determination. Roots were insed with distilled water, blotted dry, weighed and stored at $-20{ }^{\circ} \mathrm{C}$ for organic acid determination. Roots were ground in a mortar with $70 \% \mathrm{v} / \mathrm{v}$ ethanol and acid-washed sand. The mixture was centrifuged at $4000 \mathrm{rpm}$ for $10 \mathrm{~min}$, and the pellet was extracted twice with boiling water. The supernatant from each of these extractions was transferred to a rotary evaporator and concentrated at $35^{\circ} \mathrm{C}$ under vacuum. The dried residues were dissolved in bi-distilled water and filtered through a membrane 
filter $(0.2 \mu \mathrm{m})$. Concentrations of malic, citric, fumaric, and succinic acids were measured by Gas Chromatography (Mass Selective Detectors 5972 series). Each sample of the treatments with 3 replicates was analyzed twice.

\section{RESULTS AND DISCUSSION}

\section{Classification of nine rice cultivars for zinc-use efficiency:}

Nine rice cultivars were classified based on dry matter production (root plus shoot) at the low $\mathrm{Zn}$ level and $\mathrm{Zn}$-use efficiency, Table (1) and Figure (1) illustrated these results.

Table (1) Zinc use efficiency (A-B/C-D) of several rice cultivars under different zinc levels.

\begin{tabular}{|l|c|c|c|c|c|}
\hline \multicolumn{1}{|c|}{ Cultivars } & $A$ & $B$ & $C$ & $D$ & $\begin{array}{c}\text { Zn use } \\
\text { Efficiency }\end{array}$ \\
\hline 1-Giza 172 & 7.40 & 4.75 & 162.41 & 86.23 & 34.79 \\
\hline 3-Giza 176 & 6.07 & 4.77 & 168.42 & 104.67 & 20.39 \\
\hline 5-Sakha 103 & 7.17 & 4.87 & 194.78 & 108.46 & 26.59 \\
\hline 4-Giza 177 & 9.49 & 6.13 & 257.03 & 123.52 & 25.13 \\
\hline 2-Giza 171 & 8.58 & 6.17 & 215.87 & 133.77 & 29.29 \\
\hline 6-Giza 178 & 8.72 & 6.73 & 242.22 & 142.99 & 20.05 \\
\hline 7-Sakha 102 & 9.42 & 7.39 & 260.22 & 158.08 & 19.83 \\
\hline 8-Giza 181 & 8.36 & 7.59 & 227.46 & 150.59 & 9.97 \\
\hline 9-Sakha 101 & 8.49 & 7.72 & 250.56 & 152.59 & 7.81 \\
\hline
\end{tabular}

$A=$ Dry matter yield of (root + shoot) across medium and high $\mathrm{Zn}$ level (g/pot).

$B=$ Dry matter yield of (root + shoot) at low Zn level (g/pot).

$C=Z n$ accumulation in (root + shoot) across medium and high $Z n$ level ( $\mu g /$ pot).

$D=\mathrm{Zn}$ accumulation in (root + shoot) at low $\mathrm{Zn}$ level ( $\mu \mathrm{g} / \mathrm{pot}$ ).

These rice cultivars were classified into four groups as follows:

1) Efficient and non responsive : In this group are cultivars which produced dry matter yield higher than the average of nine cultivars at the low $\mathrm{Zn}$ level, but $Z n$-use efficiency was lower than the average of nine cultivars. Cultivars G178, G 181, S101 and S102 fall into this category.

2) Non efficient and responsive : in this group are cultivars which produced dry matter yield less than the average of nine cultivars at the low $\mathrm{Zn}$ level, but $Z n$-use efficiency was higher than the average of nine cultivars. Cultivars G17.2, G 171, G177 and S103 fall into this category.

3) Non efficient and non responsive : in this group are cultivars which produced dry matter yield less than the average of nine cultivars at the low $\mathrm{Zn}$ level, but $\mathrm{Zn}$-use efficiency was less than the average of nine cultivars. Cultivars $\mathrm{G} 176$ fall into this category.

4) Efficient and responsive : In this group are cultivars which produced dry matter yield higher than the average of nine cultivars at the low $\mathrm{Zn}$ level, but $\mathrm{Zn}$-use efficiency was higher than the average of nine cultivars. Non cultivars fall into this category. 


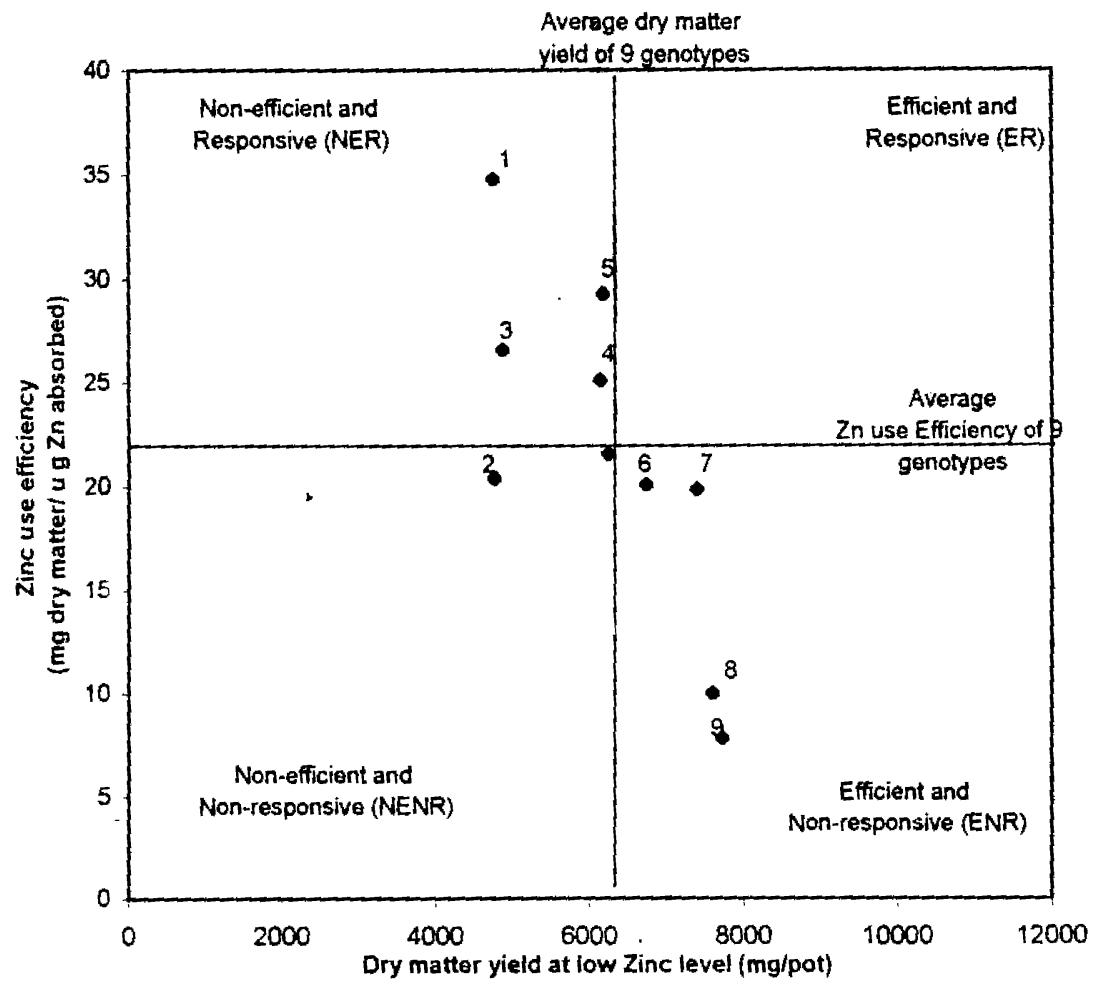

Fig.(1) Classification of several rice cultlvars for Zinc-use efficiency

\section{EFFECT OF BICARBONATE AND HIGH PH ON SHOOT AND ROOT DRY WEIGHT:-}

Shoot and root dry weight of both the Zn-efficient cultivar (S101) and the $Z n$-inefficient cultivar (G172) were significantly decreased by the treatments with bicarbonate whereas $\mathrm{pH}$ treatments had no effect for 4-and 8-days compared with control $(\mathrm{pH} \mathrm{6)}$. The decrease in shoot and root dry weights were greater when grown with bicarbonate than with high $\mathrm{pH}$ (Figures 1-2). Similar results obtained by (Hajiboland et al., 2003) and (Yang et al., 2003).

The inhibitory effect of bicarbonate on shoot dry weight of the Zn-efficient cultivar (S101) was less prominent than that of the $\mathrm{Zn}$-inefficient cultivar (G172). For instance, at day 8 of treatment, the decrease in shoot dry weight of the $\mathrm{Zn}$-efficient cultivar was around $6 \%$ for high pH treatment, $21 \%$ for 10 $\mathrm{mM}$ bicarbonate treatment and $29 \%$ for $20 \mathrm{mM}$ bicarbonate treatment, as compared with the control $(\mathrm{pH} \mathrm{6})$, the corresponding values for the $\mathrm{Zn}$ inefficient cultivar were 8,46 and $51 \%$. This finding is in agreement with the results of (Hajiboland et al., 2003) where they reported that the reduction in shoot growth due to bicarbonate treatment varied among the $\mathrm{Zn}$-efficient and Zn-inefficient cultivars. 
Bassioni, Nabila, $H$. et al.
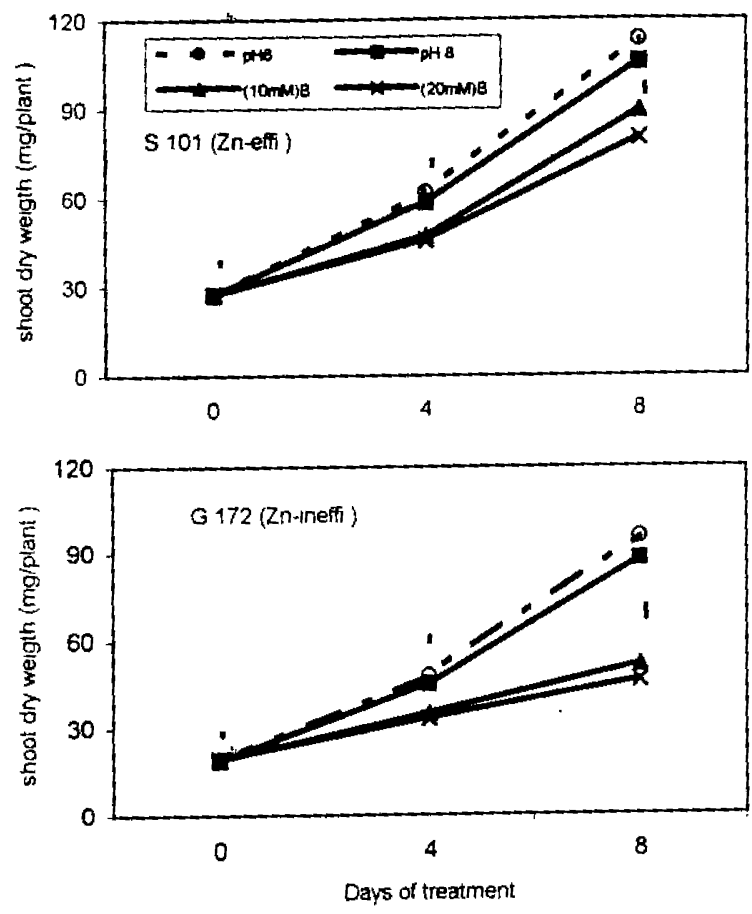

Fig (2) Effect of bicarbonate and high pH on shoot dry

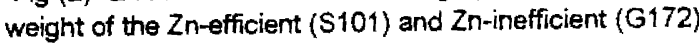
rice cultivars.

The bars depict the least significant difference (LSD, $P<0.01$ ) for the corresponding group of the data.

The inhibiting effect of bicarbonate and high $\mathrm{pH}$ treatments on root dry weight of the Zn-efficient cultivar (S101) was less prominent than that of the $\mathrm{Zn}$-inefficient cultivar (G172). For instance, at day 8 of treatment, the decrease in root dry weight of the $\mathrm{Zn}$-efficient cultivar was around $5 \%$ for the high $\mathrm{pH}$ treatment, $25 \%$ for $10 \mathrm{mM}$ bicarbonate treatment and $27 \%$ for 20 $\mathrm{mM}$ bicarbonate treatment, as compared with the control $(\mathrm{pH} \mathrm{6)}$, the corresponding values for the Zn-inefficient cultivar were 23, 60 and $69 \%$. Similar results obtained by (Yang et al., 2003).

EFFECT OF BICARBONATE AND HIGH PH ON ROOT LENGTH:-

The root length of the Zn-efficient cultivar (S101) was considerably enhanced at day 4 and 8 when plants were grown with bicarbonate, but no obvious increase in root length was found when grown with high pH treatment (Fig. 3). On the contrary, the root length of the $\mathrm{Zn}$-inefficient cultivar (G172) was obviously reduced at day 4 and dramatically reduced at day 8 of the bicarbonate or high $\mathrm{pH}$ treatments, and a greater reduction was noted for bicarbonate than for high $\mathrm{pH}$ at day 8 (Fig. 3).

The increases in root length for Zn-efficient cultivar were $54 \%$ for 10 $\mathrm{mM}$ bicarbonate treatment and $64 \%$ for $20 \mathrm{mM}$ bicarbonate treatment at day 
4 , and reached to $74 \%$ for $10 \mathrm{mM}$ bicarbonate treatment and $83 \%$ for 20 $\mathrm{mM}$ bicarbonate treatment at day 8 . The decreases in the root length for $\mathrm{Zn}$ inefficient cultivar were $13 \%$ for $10 \mathrm{mM}$ bicarbonate treatment and $42 \%$ for $20 \mathrm{mM}$ bicarbonate treatment at day 4 , and $57 \%$ for $10 \mathrm{mM}$ bicarbonate treatment and $67 \%$ for $20 \mathrm{mM}$ bicarbonate treatment at day 8 , compared with control ( $\mathrm{pH} 6)$.

The results imply that bicarbonate might be the major responsible factor for enhancing root elongation in the $\mathrm{Zn}$-efficient cultivar and inhibiting root elongation in the $\mathrm{Zn}$-inefficient cultivar. The results of this study is in agreement with that of (Yang et al., 2003); they reported that the increases in root length was $75 \%$ for $\mathrm{Zn}$-efficient rice cultivar and the reduction in root length was $47 \%$ for $\mathrm{Zn}$-inefficient rice cultivar.

The strong enhancement of root elongation by bicarbonate in the $\mathrm{Zn}$ efficier.t rice cultivar at the $\mathrm{Zn}$-deficient and moderate $\mathrm{Zn}$ levels growth in the media could help plants develop a larger root surface area and enhance root capacity for absorbing $\mathrm{Zn}$ (Hajiboland et al., 2003).
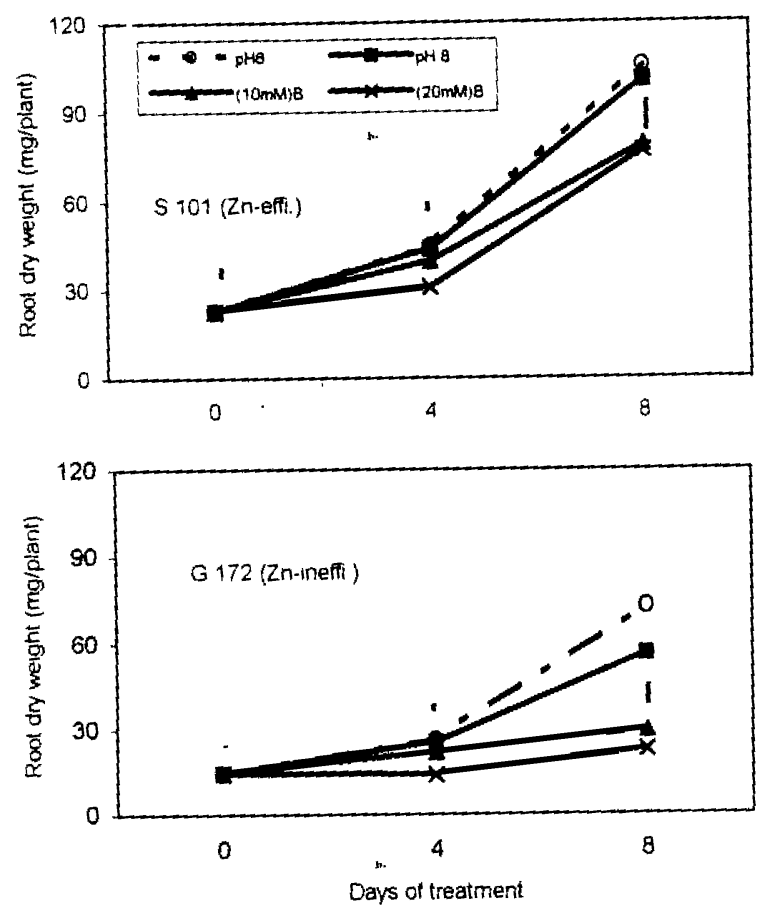

Fig (3) Effect of bicarbonate and high pH on root dry weight of the Zn-efficient (S101) and Zn-inefficient (G172) rice cultivars. The bars depict the least significant difference (LSD, $P<0.01$ ) for the corresponding group of the data. 
Bassioni, Nabila, $H$. et al.
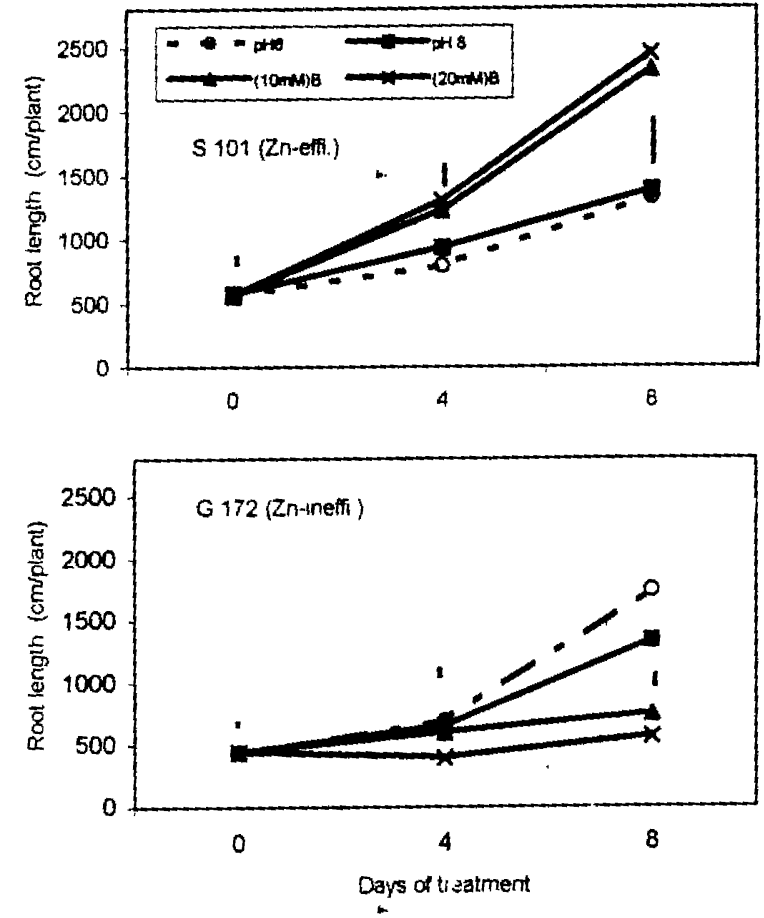

Fig (4) Effect of bicarbonate and high $\mathrm{pH}$ on root length of

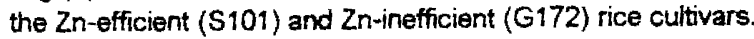

$$
\begin{aligned}
& \text { The bars depict the least significant difference (LSO, P<0.01) for } \\
& \text { the corresponding group of the data. }
\end{aligned}
$$

\section{EFFECT OF BICARBONATE AND HIGH PH ON ACCUMULATION OF ORGANIC ACIDS IN ROOTS:-}

The four major organic acids (i.e. malic, citric, fumaric and succinic acids) in rice roots are affected by bicarbonate and high pH treatments. In the roots of both $\mathrm{Zn}$-efficient and $\mathrm{Zn}$-inefficient cultivars malate was accumulated with the time.

At either day 4 or 8 , malate concentration in the roots of the $\mathrm{Zn}$-efficient cultivar was not affect by the high pH treatment, but increased on average, around three and five folds for $10,20 \mathrm{mM}$ bicarbonate treatments, respectively, compared with control (pH6) (Fig.4). Whereas, malate concentration in the root of the $\mathrm{Zn}$-inefficient cultivar increased, on average, around three fold for high $\mathrm{pH}$ treatment and up to five and six folds for 10 and $20 \mathrm{mM}$ bicarbonate treatment respectively, compared with control $(\mathrm{pH} 6)$ (Fig.4).

At day 4 , malate concentration in the root of the Zn-efficient cultivar was, on average, 4 fold less than that of the $\mathrm{Zn}$-inefficient cultivar. However, these differences were much less observed after 8 days of growth. These results were in agreement with those of Yang et al., (1994). 
J. Agric. Sci. Mansoura Univ., 31 (4), Aprii, 2006
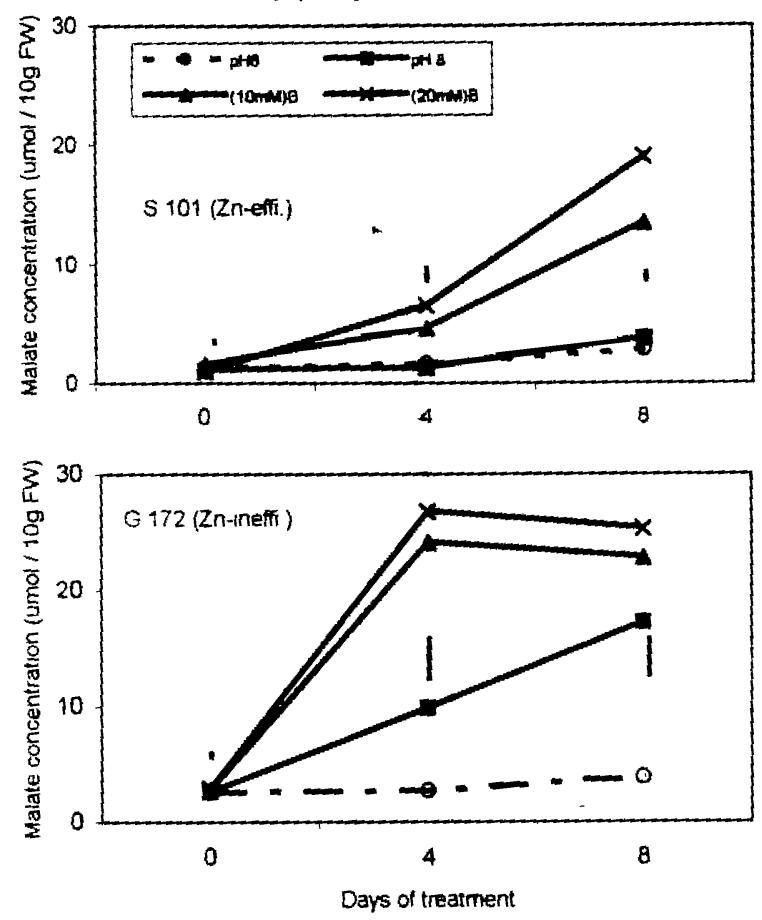

Fig (5) Effect of bicarbonate and high pH on Malate concentration in the roots of the Zn-efficient (S101) and $\mathrm{Zn}$ inefficient ( $G 172$ ) rice cultivars.

The bars depict the least significant difference (LSD, $P<0.01$ ) for the corresponding group of the data.

They reported that the synthesis of malate results from a marked activation of the cytoplasmic phosphoenolpyruvate carboxylase (dark fixation) induced by an increase in cytoplasmic bicarbonate and $\mathrm{pH}$.

In general, malate concentration in the roots of the $\mathrm{Zn}$-inefficient cultivar was, on average, around three fold greater than that of the $\mathrm{Zn}$ efficient cultivar. These results are in agreement with (Yang et al., 1994. 2003 ) they reported that at 4 and 8 days of treatment, malate accumulation in the roots of the $\mathrm{Zn}$-efficient rice cultivars was $2-3$ folds less than that of the $\mathrm{Zn}$-inefficient rice cultivars.

Large difference occurred in citrate concentration in the roots of $\mathrm{Zn}$ inefficient and $\mathrm{Zn}$-efficient treated with high $\mathrm{pH}$ and bicarbonate treatments (Fig.5). For the $\mathrm{Zn}$-inefficient cultivar, citrate concentration in the roots reached its peak at day 4 for $20 \mathrm{mM}$ bicarbonate and increased continually for high $\mathrm{pH}$ and bicarbonate treatments with the time.

Bicarbonate and high $\mathrm{pH}$ treatments had the most prominent influence on citrate concentration in the root of $\mathrm{Zn}$-inefficient. After 4 and 8 days of treatment the citrate concentration in the roots of $\mathrm{Zn}$-inefficient cultivar increased, on average, 7,14 and 33 folds at high $\mathrm{pH}, 10$ and $20 \mathrm{mM}$ 


\section{Bassioni, Nabila, H. et al.}

bicarbonate treatments, respectively, whereas, citrate concentration in roots of Zi-efficient was four fold at $20 \mathrm{mM}$ bicarbonate treatment compared with control ( $\mathrm{pH} \mathrm{6)}$. But no obvious difference in citrate concentration of the $\mathrm{Zn}$ efficient cultivar was observed between high $\mathrm{pH}$ and $10 \mathrm{mM}$ bicarbonate treatments compared with control $(\mathrm{pH} 6)$. Similar results obtained by Yang et al., (2003)

The other two organic acids which responsed to bicarbonate and high $\mathrm{pH}$ treatments in rice roots included succinate and fumarate. Fumarate takes the same trend of malate and citrate of $\mathrm{Zn}$-inefficient cultivar. At 4 to 8 days, fumarate concentration in the roots of $\mathrm{Zn}$-inefficient cultivar increased around 3 to 5 folds with high pH treatment and up to 6 to 7 and 7.7 to 8 folds with 10 , $20 \mathrm{mM}$ bicarbonate treatments, respectively. Whereas, fumarate concentration in roots of $\mathrm{Zn}$-efficient reached its peak at day 4 for high $\mathrm{pH}$ and bicarbonate treatments and decreased ( Fig.6).

In both cultivars ( $\mathrm{Zn}$-inefficient and $\mathrm{Zn}$-efficient) bicarbonate treatments caused more fumarate accumulation than high $\mathrm{pH}$ treatment. Bicarbonate induced much more fumarate accumulation in the roots of the $\mathrm{Zn}$-inefficient cultivar than that of the $\mathrm{Zn}$-efficient cultivar at 4 and 8 days.
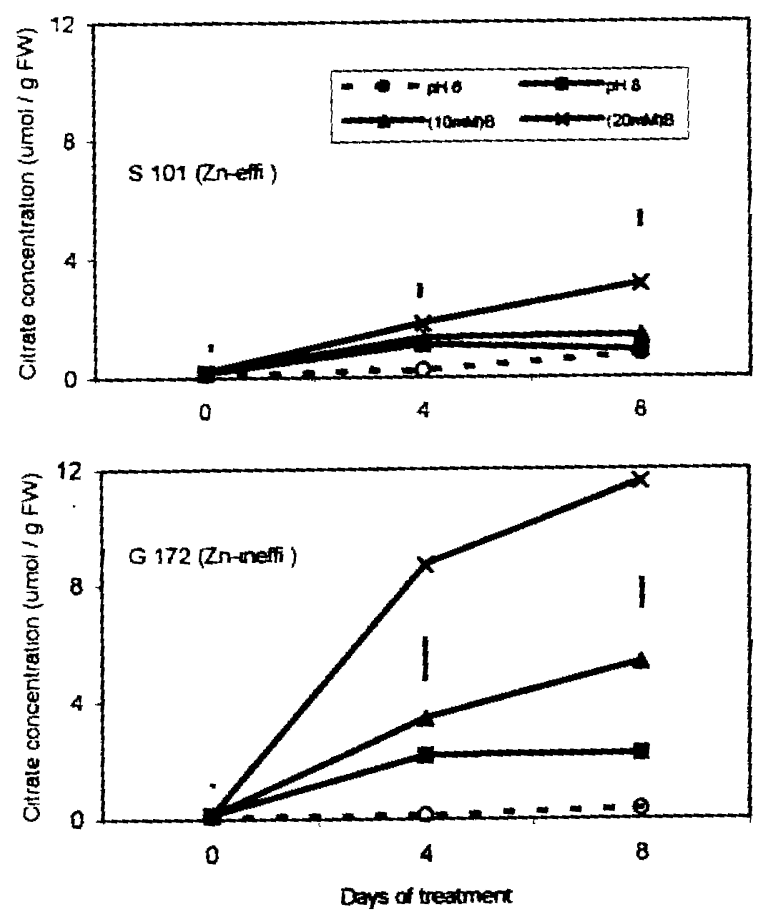

Fig (6) Effect of bicarbonate and high pH on citrate concentration in the roots of the $\mathrm{Zn}$-efficient (S101) and $\mathrm{Zn}$ inefficient (G172) rice cultivars

The bars depict the least significant ofierence (LSD, P<0.01) for the corresponding group of the data. 
J. Agric. Sci. Mansoura Univ., 31 (4), April, 2006
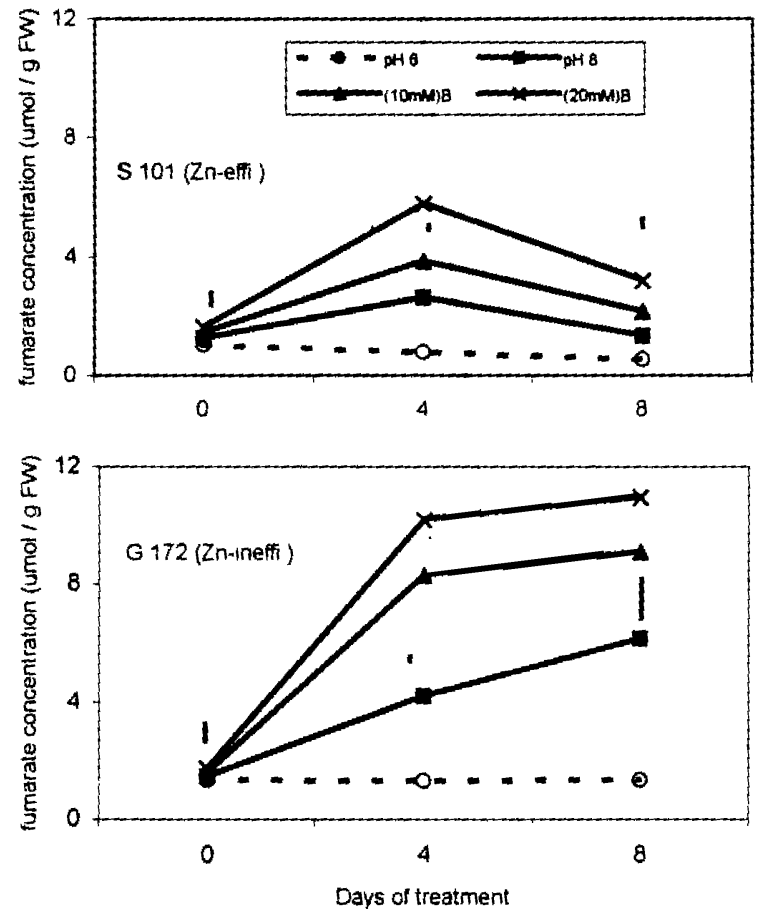

Fig ( 7) Effect of bicarbonate and high pH on fumarate concentration in the roots of the $\mathrm{Zn}$-efficient (S101) and $\mathrm{Zn}$ inefficient (G172) rice cultivars

The bars depict the least significant difference (LSD, $P<0.01$ ) for the corresponding group of the data.

Succinate concentration was much lower than that other organic acids in the rice roots for $\mathrm{Zn}$-inefficient and $\mathrm{Zn}$-efficient. Succinate concentration in the roots of the $\mathrm{Zn}$-inefficient cultivar increased by $60 \%$ and $80 \%$ for high pH treatment, and up to $90 \%$ and $96 \%$ for $10 \mathrm{mM}$ bicarbonate at day 4 and 8 , respectively. In case of the $20 \mathrm{mM}$ bicarbonate treatment succinate concentration reached a peak at day 4 (Fig.7), then leveled off. Succinate concentration in the roots of the $\mathrm{Zn}$-efficient cultivar increased, on average, $30 \%$ for high pH treatment, and up to $40 \%$ and $110 \%$ for 10 and $20 \mathrm{mM}$ bicarbonate treatments, respectively, compared with control $(\mathrm{pH} 6)$.

No significant difference in succinate concentration of the $\mathrm{Zn}$-efficient cultivar was observed between high $\mathrm{pH}$ and $10 \mathrm{mM}$ bicarbonate treatments at 4 and 8 days, whereas, in the $\mathrm{Zn}$-inefficent no significant difference in succinate concentration was observed between high $\mathrm{pH}$ and $10 \mathrm{mM}$ bicarbonate treatment at day 8 only but there is a significant difference in day4. 


\section{Bassioni, Nabila, $\boldsymbol{H}$. et al.}
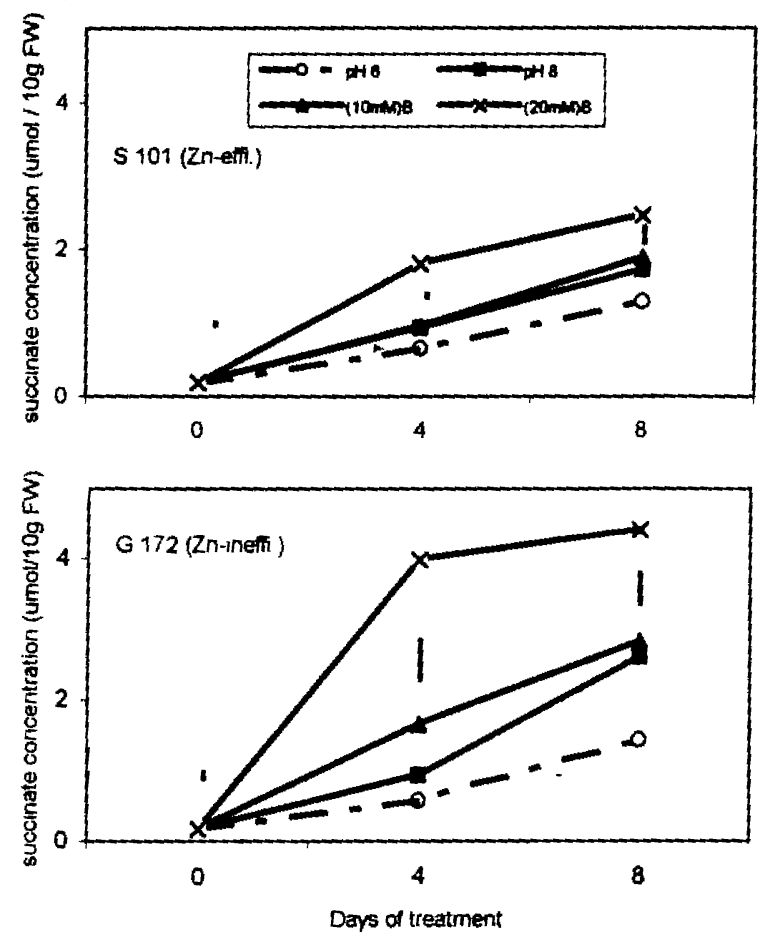

Fig (8) Effect of bicarbonate and high pH on succinate concentration in the roots of the $\mathrm{Zn}$-efficient (S101) and $\mathrm{Zn}$ inefficient (G172) rice cultivars.cultivars

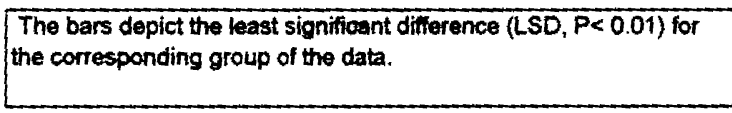

\section{REFERENCES}

Dogar, M. A.; and T. V. Hai (1980). Effect of N,P and $\mathrm{HCO}_{3}$ levels in the nutrient solution on rate of $\mathrm{Zn}$ absorption by rice roots and $\mathrm{Zn}$ content. Z. pflanzenphysiol. 98: 203-212.

Forno, D. A.; S. Yoshida and C. J. Asher (1975). Zinc deficiency in rice. I. Soil factors associated with the deficiency. Plant Soil, 42: 551-563.

Gout, E.; Blignly, R; N. Pascal and K. Douce (1992). Regulation of intracellular $\mathrm{pH}$ values in higher plant cells. Carbon-13 and phosphours-31 nuclear magnetic resonance studies. J. Biol. Chem. 267:13903-13909.

Graham R.D.; J. S. Asher and S. C. Hynes (1992). Selection zinc-efficient cereal genotypes for soil of low zinc status. Plant Soil, 146: 241-250.

Hajiboland, R.; X. E.Yang and Romheld, V. (2003). Effects of bicarbonate and high $\mathrm{pH}$ on growth of $\mathrm{zn}$-efficient and $\mathrm{zn}$-inefficient genotypes of rice, wheat and rye. Plant and Soil 250: 349-357. 
Lee, J.; and H. W.Woolhouse (1969a). acomparative study of bicarbonate inhibition of root growth in calcicale and calcifuges grasses. New Phytol., 68:1-11.

Newman, E. I. (1966). A method of estimating the total length of root in a sample. J. Appl. E col. 3:139-145.

Qin, S. C. (1988). Zinc deficiency in lowland rice and its correction. In Diagnosis and correction of Nutritional Disorders in crops; Qin, S. C., Ed.; Zhejaing Academic press; Hanzhou, China; 118-128.

Sobby, A. Gh.; T. B. Abd El-Azeem and A. N. Mohamed (2002). Rice in Egypt, P112.

Yang, X.; R. Hajiboland and V. Romheld (2003). Bicarbonate had greater effects than high $\mathrm{pH}$ on inhibiting root growth of zinc-inefficient rice genotype. J. of Plant Nutr. 26: (2), 399-415.

Yang, X. ; V. Romheld and H.Marschner (1994). Effect of 'bicarbonate on root growth and accumulation of organic acids in $\mathrm{Zn}$-inefficient and $\mathrm{Zn}$ efficient rice cultivars (Oryza Sativa L.). Plant Soil, 164:1-7.

Yoshida, S.; D.Forno A.; J. M.Cock and K.Gomez (1972). Laboratory manual for physiological studies of rice. $2^{\text {nd }}$ Ed., The international Rice Research Institute, Los Banos, Laguna, Philippine p.p 53-57.

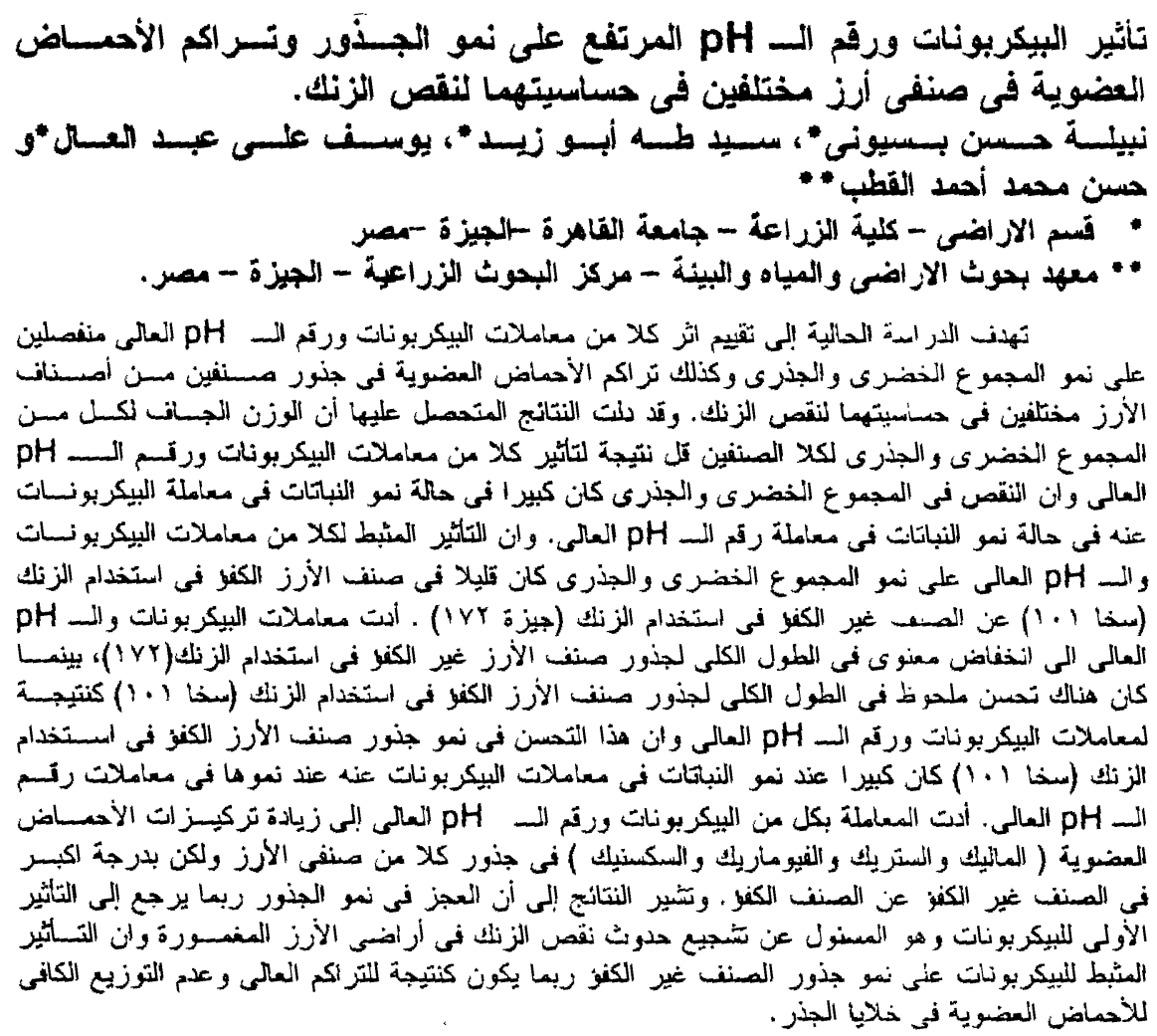

